\title{
Analysis of Functionally Graded Material Plate under Transverse Load for Various Boundary Conditions
}

\author{
Manish Bhandari ${ }^{1}$ Dr. Kamlesh Purohit ${ }^{2}$ \\ Associate Professor ${ }^{l}$ Jodhpur Institute of Technology, Jodhpur, Rajasthan \\ Professor $^{2} \&$ HOD, Jai Narain Vyas University, Jodhpur, Rajasthan
}

\begin{abstract}
Functionally gradient materials (FGM) are one of the most widely used materials in various applications because of their adaptability to different situations by changing the material constituents as per the requirement. Most structural components used in the field of engineering can be classified as beams, plates, or shells for analysis purposes. In the present study the power law, sigmoid and exponential distribution is considered for the volume fraction distributions of the functionally graded plates. The work includes parametric studies performed by varying volume fraction distributions and boundary conditions. Also static analysis of functionally gradient material plate is carried out by sigmoid law and verified with the published results. The convergence study of the results is optimized by changing the mesh size and layer size. Power law and exponential law are applied for the same material and set of conditions.
\end{abstract}

Keyword: A. Functional composites C. Elastic properties C. Finite element analysis (FEA)

\section{Introduction}

The material property of the FGM can be tailored to accomplish the specific demands in various engineering utilizations to achieve the advantage of the properties of individual material. This is possible due to the material composition of the FGM changes sequentially in a preferred direction. The thermo-mechanical deformation of FGM structures have attracted the attention of many researchers in the past few years in different engineering applications which include design of aerospace structures, heat engine components and nuclear power plants etc. A huge amount of published literature observed for evaluation of thermomechanical behavior of functionally gradient material plate using finite element techniques. It includes both linearity and non linearity in various areas. A few of published literature highlights the importance of topic. A number of approaches have been employed to study the static bending problems of FGM plates. The assessment of thermo-mechanical deformation behavior of functionally graded plate structures considerably depends on the plate model kinematics. G. N. Praveen and J. N. Reddy (1997) reported that the response of the plates with material properties between those of the ceramic and metal is not intermediate to the responses of the ceramic and metal plates [1]. J. N. Reddy (1998) reported theoretical formulations and finite element analysis of the thermomechanical, transient response of functionally graded cylinders and plates with nonlinearity [2]. Z.-Q. Cheng, R.C. Batra (1999), developed a new solution in closed form for the functionally graded elliptic plate rigidly clamped at the edges.It was found that thein-plane displacements and transverse shear stresses in a functionally graded plate do not agree with those assumed in classical and shear deformation plate theories [3]. J. N. Reddy (2000) formulated Navier's solutions in conjunction with Finite element models of rectangular plates based on the third-order shear deformation plate theory for functionally graded plates [4]. Bhavani V. Sankar (2002) solved the thermoelastic equilibrium equations for a functionally graded beam in closed-form to obtain the axial stress distribution [5]. L.F. Qian, R.C. Batra, L.M. Chen (2004) analyzed static deformations, free and forced vibrations of a thick rectangular functionally graded elastic plate by using a higher order shear and normal deformable plate theory and a meshless local Petrov-Galerkin (MLPG) method [6].A.J.M. Ferreira, R.C. Batra, C.M.C. Roque, L.F. Qian, P.A.L.S. Martins (2005), presented the use of the collocation method with the radial basis functions to analyze several plate and beam problems with a third-order shear deformation plate theory (TSDT) [7]. M. Tahani1, M. A. Torabizadeh and A. Fereidoon (2006), developedanalytical method to analyze analytically displacements and stresses in a functionally graded composite beam subjected to transverse load and the results obtained from this method were compared with the finite element solution done by ANSYS [8]. Shyang-Ho Chi, Yen-Ling Chung (2006) evaluated the numerical solutions directly from theoretical formulations and calculated by finite element method using MARC program.Besides, they compared the results of P-FGM, S-FGM and E-FGM [9] [10]. Hui Wang, Qing-Hua Qin (2007) developed a meshless algorithm to simulate the static thermal stress distribution in two-dimensional (2D) functionally graded materials (FGMs). The analog equation method (AEM) was used to obtain the equivalent homogeneous system to the original nonhomogeneous equation [11]. Yasser M. Shabana, Naotake Noda (2008) used the homogenization method (HM) based on the finite element method (FEM) to determine the full set of the macroscopic effective properties which lead to the same thermomechanical behavior as the one 
of the material with the periodic microstructure [12]. M. Mahdavian (2009), derived equilibrium and stability equations of a FGM rectangular plate under uniform in-plane compression [13]. Ashraf M. Zenkour and Daoud S. Mashat (2010) determined the thermal buckling response of functionally graded plates using sinusoidal shear deformation plate theory (SPT) [14]. S.S. Alieldin, A.E. Alshorbagy, M. Shaat (2011), proposed three transformation procedures of a laminated composite plate to an equivalent single-layer FG plate. The first approach is a curve fitting approach which is used to obtain an equivalent function of the FG material property, the second approach is the effective material property approach and the third approach is the volume fraction approach in which the FG material property varies through the plate thickness with the power law [15]. Kyung-Su Na, and Ji-Hwan Kim (2011) reported stress analysis of functionally graded composite plates composed of ceramic, functionally graded material and metal layers using finite element method. Numerical results were compared for three types of materials. The 18-node solid element was selected for more accurate modeling of material properties in the thickness direction [16]. Vanam B. C. L., Rajyalakshmi M. and Inala R. (2012) analyzed the static analysis of an isotropic rectangular plate with various boundary conditions and various types of load applications. Numerical analysis (finite element analysis, FEA) has been carried out by developing programming in mathematical software MATLAB and they compared results with that were obtained by finite element analysis software ANSYS [17]. MostaphaRaki, Reza Alipour and AmirabbasKamanbedast (2012), derived equilibrium and stability equations of a rectangular plate made of functionally graded material (FGM) under thermal loads based on the higher order shear deformation plate theory [18]. Mohammad Talha and B N Singh (2012) reported formulations based on higher order shear deformation theory with a considerable amendment in the transverse displacement using finite element method (FEM) [19].Srinivas.G and Shiva Prasad.U (2012) focused on analysis of FGM flat plates under mechanical loading in order to understand the effect variation of material properties on structural response using ANSYS software [20]. Srinivas.G and Shiva Prasad.U (2013) focused on analysis of FGM flat plates under thermal loading in order to understand the effect variation of material properties has on structural response. Results are compared to published results in order to show the accuracy of modeling FGMs using ANSYS software [21].

In the present study the power law, sigmoid and exponential distribution is considered for the volume fraction distributions of the functionally graded plates. The studies include analysis of the response of structural element specifically plates made of functionally graded materials. The work includes parametric studies performed by varying volume fraction distributions and boundary conditions. The finite element software ANSYS APDL-13 is used for the modeling and analysis purpose.

\section{Material gradient of FGMplates}

The effective material properties like Young's modulus, Poisson's ratio, coefficient of thermal expansion, thermal conductivity etc. on the upper and lower surfaces are different but are preassigned. However, the Young's modulus and Poisson's ratio of the plates vary continuously only in the thickness direction (z-axis) i.e.E $=\mathrm{E}(\mathrm{z}), v=v(\mathrm{z})$. However, the Young's moduli in the thickness direction of the FGM plates vary with power-law functions (P-FGM), exponential functions (E-FGM), or with sigmoid functions (S-FGM).A mixture of the two materials composes the through the thickness characteristics. The FGM plate of thickness ' $h$ ' is modeled usually with one side of the material as ceramic and the other side as metal.

\subsection{Power Law}

The material properties of a P-FGM can be determined by the rule of mixture:

$$
\mathrm{P}(\mathrm{z})=\left(\mathrm{P}_{\mathrm{t}}-\mathrm{P}_{\mathrm{b}}\right) \mathrm{V}_{\mathrm{f}}+\mathrm{P}_{\mathrm{b}}
$$

Material properties are dependent on the volume fraction $\mathrm{V}_{\mathrm{f}}$ of P-FGM which obeys power law $\mathrm{V}_{\mathrm{f}}=(\mathrm{z} / \mathrm{h}+1 / 2)^{\mathrm{n}}$

where $\mathrm{n}$ is a parameter that dictates the material variation profile through the thickness known as is the volume fraction exponent. At bottom face, $(\mathrm{z} / \mathrm{h})=-1 / 2$ and $\mathrm{V}_{\mathrm{f}}=0$, hence $\mathrm{P}(\mathrm{z})=\mathrm{P}_{\mathrm{b}}$ and At top face, $(\mathrm{z} / \mathrm{h})=1 / 2$ and so $\mathrm{V}_{\mathrm{f}}$ $=1$, hence $\mathrm{P}(\mathrm{z})=\mathrm{P}_{\mathrm{t}}$ where $\mathrm{P}$ denotes a generic material property like modulus, $\mathrm{P}_{t}$ and $\mathrm{P}_{\mathrm{b}}$ denote the property of the top and bottom faces of the plate. 


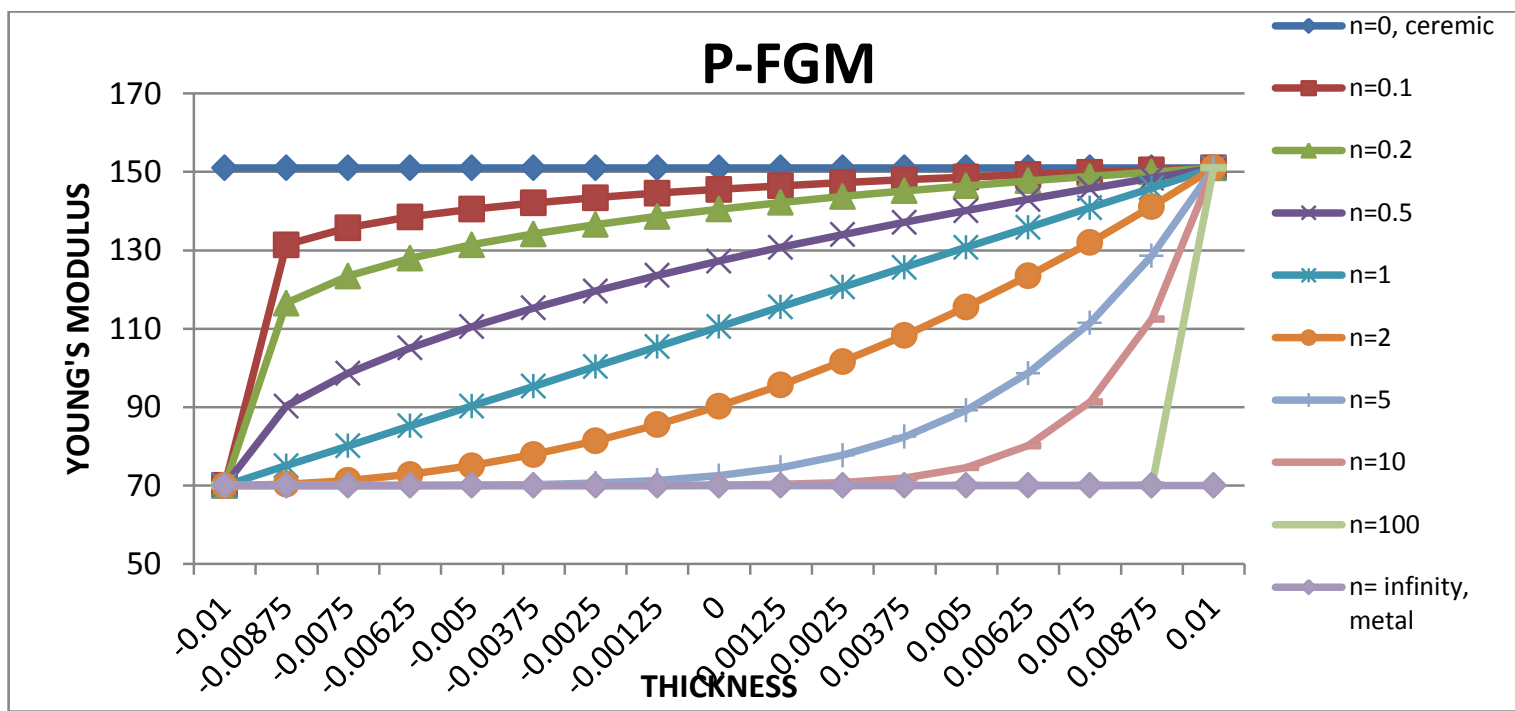

Figure1:Variation of Young's modulus in a P-FGM with ' $n$ '.

At $n=0$ the plate is a fully ceramic plate while at $n=\infty$ the plate is fully metal. The variation of Young's modulus in the thickness direction of the P-FGM plate is depicted in Figure 1., which shows that the Young's modulus changes rapidly near the lowest surface for $n>1$, and increases quickly near the top surface for $n<1$.

\subsection{Sigmoid Law:}

In the case of adding an FGM of a single power-law function to the multi-layered composite, stress concentrations appear on one of the interfaces where the material is continuous but changes rapidly .Therefore, Chung and Chi (2001) defined the volume fraction using two power-law functions to ensure smooth distribution of stresses among all the interfaces. The two power law functions are defined by:

$g_{1}(z)=1-\frac{1}{2}\left(\frac{\frac{h}{2}-z}{\frac{h}{2}}\right)^{p}$ for $0 \leq \mathrm{z} \leq \mathrm{h} / 2, g_{2}(z)=\frac{1}{2}\left(\frac{\frac{h}{2}+z}{\frac{h}{2}}\right)^{p} \quad$ for $-\mathrm{h} / 2 \leq \mathrm{z} \leq 0$

By using the rule of mixture, the Young's modulus of the S-FGM can be calculated by: $E(z)=g_{1}(z) E_{1}+\left[1-g_{1}(z)\right] E_{2}$ for $0 \leq \mathrm{z} \leq \mathrm{h} / 2$ and $E(z)=g_{2}(z) E_{1}+\left[1-g_{2}(z)\right] E_{2}$ for $-\mathrm{h} / 2 \leq \mathrm{z} \leq 0$

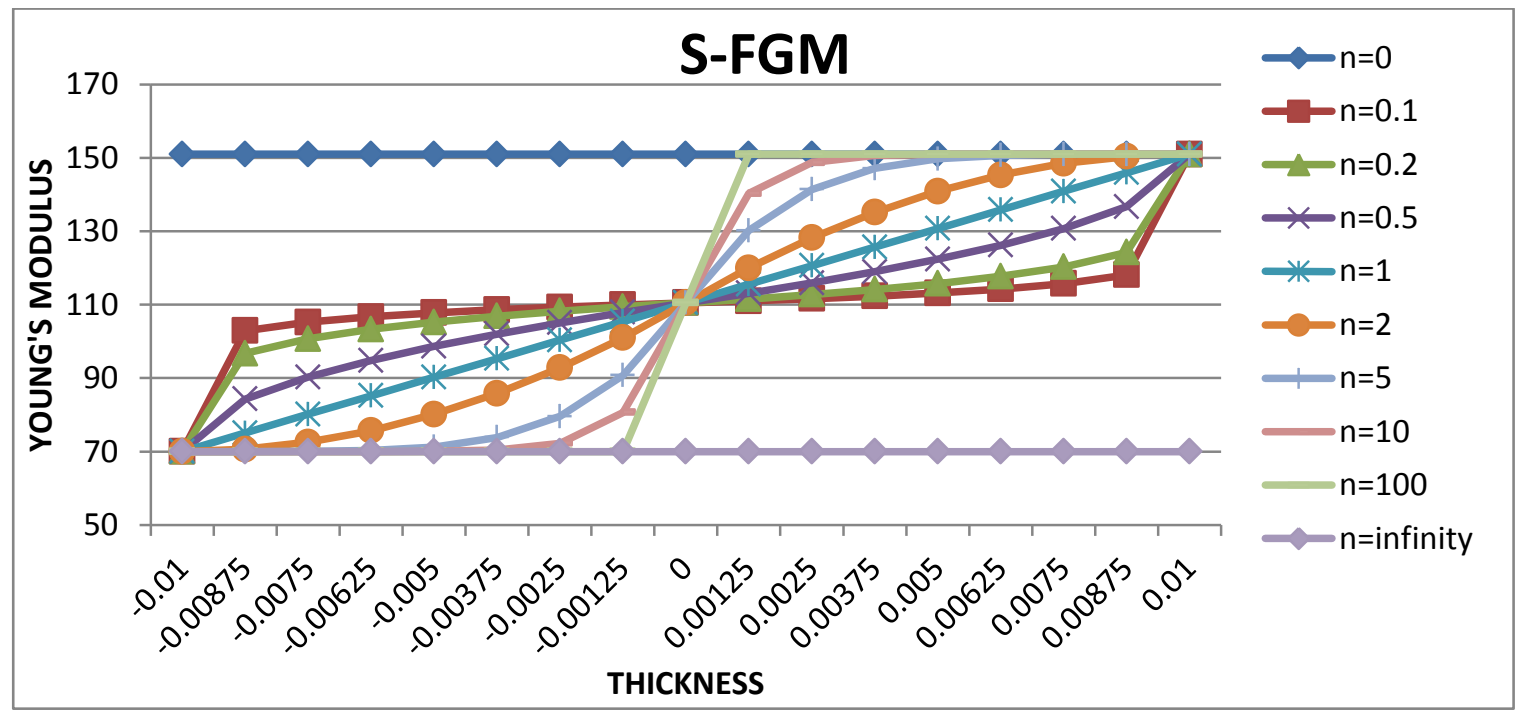

Figure 2. Variation of Young's modulus in a S-FGM with 'n'. 
The variation of Young's modulus in the thickness direction of the S-FGM plate is depicted in Figure2., which shows that the Young's modulus changes are gradual because of using two power law functions together as described above.

\subsection{Exponential Law:}

Many researchers used the exponential function to describe the material properties of FGMs as follows: $E(z)=E_{2} e^{\frac{1}{h} \ln \left(\frac{E_{1}}{E_{2}}\right)(z+h / 2)}$

The material distribution in the E-FGM plates is plotted in Figure 3.

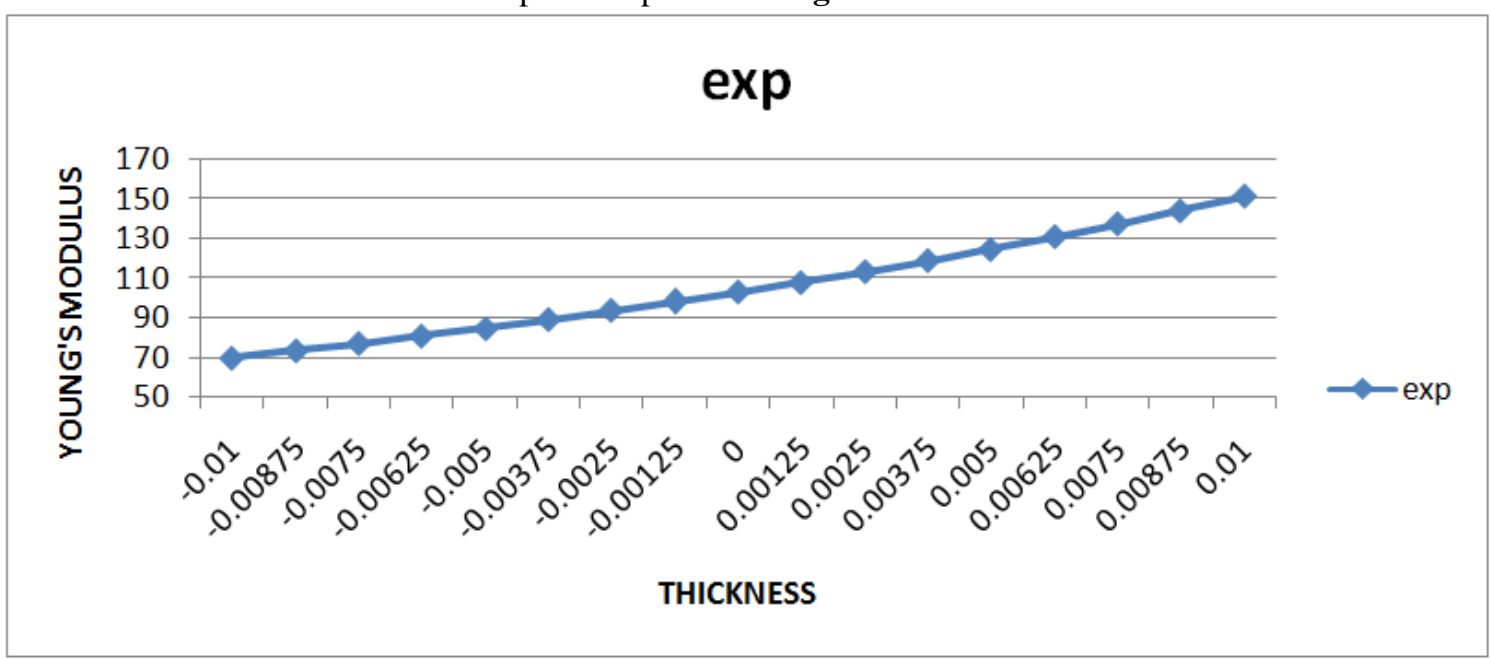

Figure 3.Variation of Young's modulus in a E-FGM plate.

\section{Finite Element Modeling Technique}

The material properties of the FGM change throughout the thickness, the numerical model is to be broken up into various "layers" in order to capture the change in properties. These "layers" capture a finite portion of the thickness and are treated like isotropic materials. Material properties are calculated from the bottom surface using the various volume fraction distribution laws. The "layers" and their associated properties are then layered together to establish the through-the-thickness variation of material properties. Although the layered structure does not reflect the gradual change in material properties, a sufficient number of "layers" can reasonably approximate the material gradation. In this paper, the modeling and analysis of FGM plate is carried out using ANSYS software. ANSYS offers a number of elements to choose from for the modeling of gradient materials. The FGM characteristics under mechanical and thermal loads studied on a flat plate were modeled in 3-D.

\section{Comparative study}

To ascertain the accuracy and proficiency of the present finite element formulation, two examples have been analyzed for thermo-mechanical deformations of the FGM plates.

Example 1: We first consider the accuracy of the present finite element formulation by comparing the results with those given by A.J.M. Ferreira, R.C. Batra, C.M.C. Roque, L.F. Qian and P.A.L.S. Martins (2005). It is based on the meshless collocation method and a third-order shear deformation theory. In this example, the analysis is performed on a square functionally graded plate simply supported at all its edges (SSSS) for side to thickness ratio $a / h=20$, volume fraction index $n=0$ (ceramic), $0.5,1.0,2$, and $\infty$ (metal) with aspect ratio $a / b=$ 1 where $h$ is the thickness of the plate. The top surface of the plate is ceramic-rich, whereas the bottom surface is metal-rich. The plate is comprised of metal (Aluminium) and Ceramic (Zirconia). The material properties are taken as $E_{b}=70 \times 10^{9} \mathrm{~N} / \mathrm{m}^{2}$ for Aluminium, and $E_{t}=151 \times 10^{9} \mathrm{~N} / \mathrm{m}^{2}$ for ceramic. Poisson's ratio for both the materials have been taken as $v=0.3$. The transverse displacement $\mathrm{u}_{\mathrm{z}}$ has been non-dimensional as follows: $\overline{u z}=$ $\mathrm{u}_{\mathrm{z}} / \mathrm{h}$. The comparison of present results with published results is presented in Table $\mathbf{1}$ which shows the agreement between the two results is excellent. The difference between the two results is below $3 \%$. The results show that the performance of the present formulation is very good in terms of solution accuracy. 
Analysis of Functionally graded material plate under transverse load for various boundary

Table 1.Comparison of Present Results With published results

\begin{tabular}{|c|c|c|c|}
\hline Volume Fraction Exponent (n) & Published Results & Present Results & \% Difference \\
\hline Ceramic (0) & 0.0205 & 0.021 & 2.43 \\
\hline 0.5 & 0.0262 & 0.0268 & 2.29 \\
\hline 1 & 0.0294 & 0.0302 & 2.72 \\
\hline 2 & 0.0323 & 0.0332 & 2.79 \\
\hline Metal $(\infty)$ & 0.0443 & 0.0456 & 2.93 \\
\hline
\end{tabular}

\section{Convergence study}

Example 2: The convergence study with respect to varying mesh size and number of layers has been carried out. The obtained results are compared with those given by Shyang-Ho Chi, Yen-Ling Chung (2006). In this example, the analysis is performed on a square functionally graded plate simply supported at all its edges (SSSS) for side to thickness ratio $a / h=50$, volume fraction index $n=2$ with varying aspect ratio $(a / h)$ where $h$ is the thickness of the plate. The material properties are taken as $E_{\text {bottom }}=210 \times 10^{9} \mathrm{~N} / \mathrm{m}^{2}$ and $E_{\text {top }}=21 \times 10^{9} \mathrm{~N} / \mathrm{m}^{2}$. Poisson's ratio have been taken constant as $v=0.3$. The transverse displacement $\mathrm{u}_{\mathrm{z}}$ and stress have been nondimensional as follows: $\overline{u z}=\mathrm{u}_{\mathrm{z}} / \mathrm{h}$, and $\bar{p}=\mathbf{s}_{\mathbf{y}} / \boldsymbol{p}$. The comparison of present results with published results is presented in Figure 4 and Figure 5.

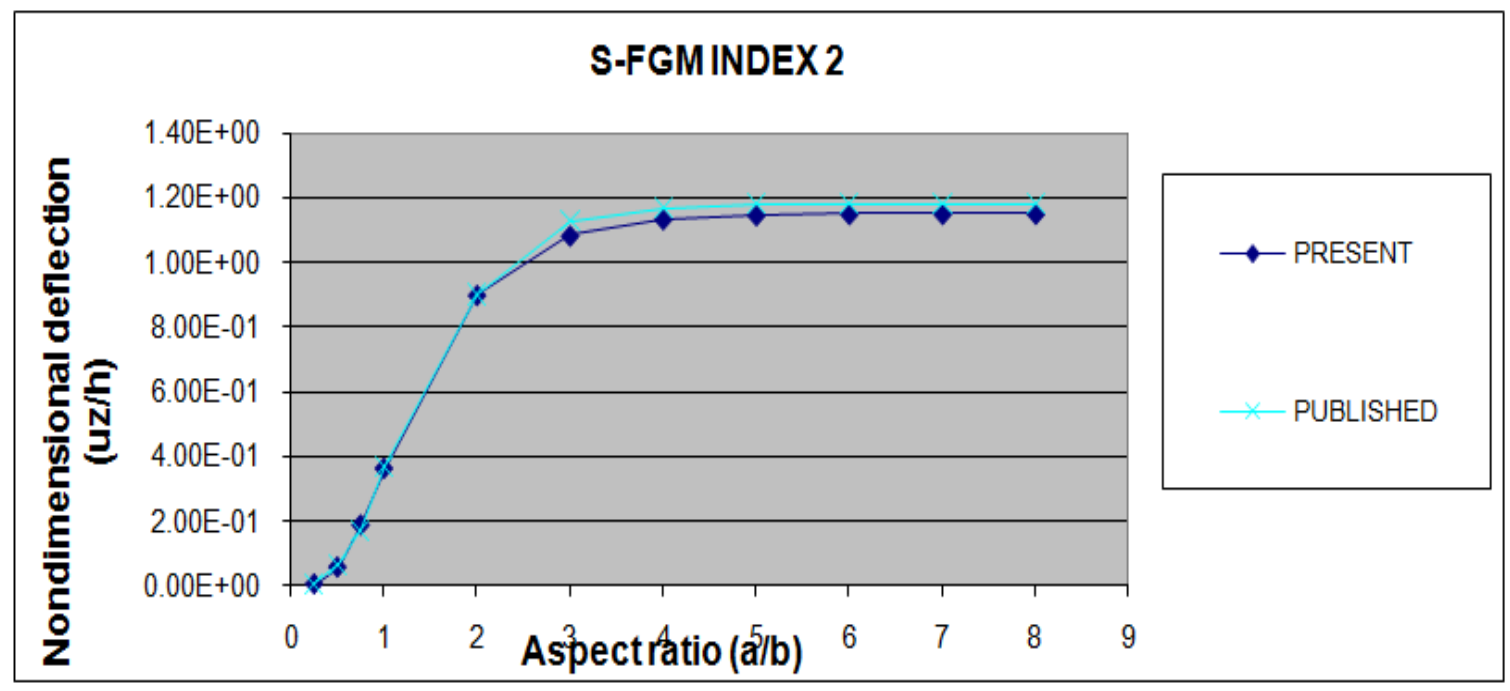

Figure 4. The maximum deflection of an S-FGM plate versus the aspect ratio $(\mathrm{a} / \mathrm{h})$

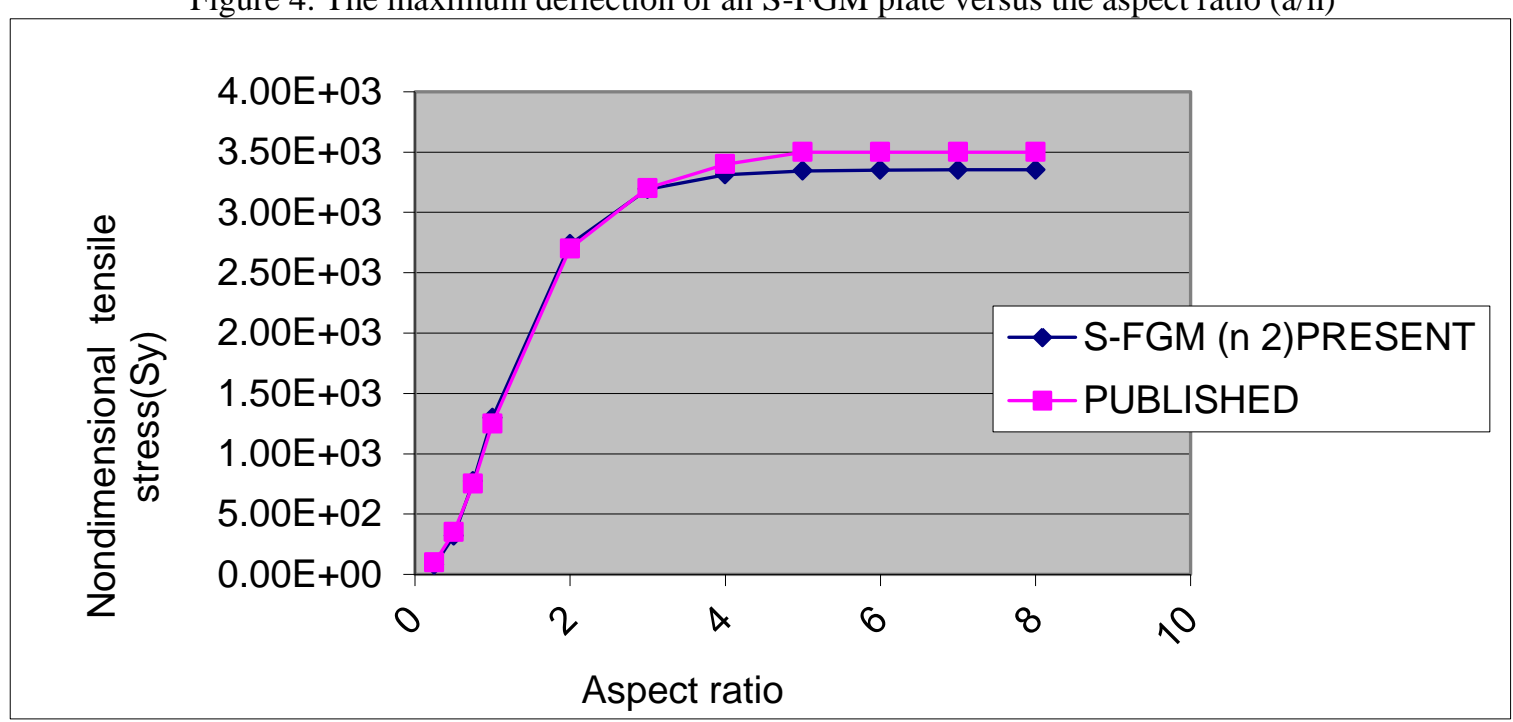

Figure5. The maximum tensile stress of an S-FGM plate versus the aspect ratio $(\mathrm{a} / \mathrm{h})$

Figure 4 and Figure 5 show the variation of maximum deflection and maximum tensile stress for varying aspect ratio $(\mathrm{a} / \mathrm{h})$. An excellent agreement between the present and published results can be observed. The results show that the performance of the present formulation is very good in terms of solution accuracy. 
Table 2: Convergence study of simply supported FGM plate with respect to mesh size.

\begin{tabular}{|c|c|c|c|c|c|c|c|}
\hline Parameters & $6 \mathrm{X} 6$ & $10 \mathrm{X} 10$ & $20 \mathrm{X} 20$ & $50 \mathrm{X} 50$ & $100 \mathrm{X} 100$ & $\begin{array}{l}\text { Published } \\
\text { Results }\end{array}$ & $\%$ Difference \\
\hline $\mathrm{u}_{\mathrm{x}}\left(\mathrm{X} 10^{-5}\right)$ & 7.97 & 7.95 & 7.96 & 7.99 & 8.01 & 8.03 & 0.25 \\
\hline $\mathrm{u}_{\mathrm{z}}\left(\mathrm{X} 10^{-3}\right)$ & 7.20 & 7.21 & 7.22 & 7.26 & 7.28 & 7.38 & 1.37 \\
\hline $\mathrm{S}_{\mathrm{x}}\left(\mathrm{X} 10^{8}\right)$ & 1.21 & 1.26 & 1.29 & 1.30 & 1.31 & 1.35 & 2.74 \\
\hline $\mathrm{e}_{\mathrm{x}}\left(\mathrm{X} 10^{-4}\right)$ & 4.10 & 4.27 & 4.35 & 4.39 & 4.41 & 4.44 & 0.79 \\
\hline
\end{tabular}

In Table 2 the results for transverse deflection, stress and strain are presented for various mesh size. Table 2 shows that as the mesh size increases, the obtained results converge towards the published results. The difference between the two results for transverse deflection below $1.5 \%$ and the difference between the two results for tensile stress is below 3\% which shows the agreement between the two results is excellent. The results show that the performance of the present formulation is very good in terms of solution accuracy. Hence finer mesh will help in attaining accurate results. Since higher mesh gives better results, 100X100 mesh is considered for the present work. The convergence study with respect to varying number of layers is shown in Table 3. The FGM plate is modeled considering 4,8 and 16 layers with a mesh size of $100 \times 100$. In Table 3 the results for transverse deflection, stress and strain are presented. The difference between the two results for transverse deflection is below $2.5 \%$ and the difference between the two results for tensile stress is below $2 \%$.

Table 3 shows that as the number of layers increases, the obtained results converge towards the published results. Since higher number of layers gives better results, 16 layers have been used in the present work. Therefore, based on the convergence study of mesh size and no. of layers, it is concluded that $(100 \times 100)$ mesh and 16 no. of layers are acceptable for thermoechanical deformation behavior of the FGM plate.

Table 3 : Convergence study of simply supported FGM plate with respect to no. of layers.

\begin{tabular}{|c|l|l|l|l|l|}
\hline Parameters & 4 layers & 8 layers & 16 layers & Published Results & \% Difference \\
\hline $\mathrm{u}_{\mathrm{x}}\left(\mathrm{X} 10^{-5}\right)$ & 6.88 & 7.99 & 8.30 & 8.03 & 3.25 \\
\hline $\mathrm{u}_{\mathrm{z}}\left(\mathrm{X} 10^{-3}\right)$ & 6.77 & 7.26 & 7.40 & 7.38 & 2.41 \\
\hline $\mathrm{S}_{\mathrm{x}}\left(\mathrm{X} 10^{8}\right)$ & 1.20 & 1.30 & 1.33 & 1.35 & $\mathbf{- 1 . 8 9}$ \\
\hline $\mathrm{e}_{\mathrm{x}}\left(\mathrm{X} 10^{-4}\right)$ & 4.25 & 4.39 & 4.43 & 4.44 & $\mathbf{- 2 . 2 6}$ \\
\hline
\end{tabular}

VI. Results and analysis

The mechanical analysis is conducted for FGM made of combination of metal and ceramic. The metal and ceramic chosen are Aluminum and Zirconia respectively. The Young's modulus for Aluminum $\left(\mathrm{E}_{\mathrm{m}}\right)$ is 70 $\mathrm{GPa}$ and for Zirconia $\left(\mathrm{E}_{\mathrm{c}}\right) 151 \mathrm{GPa}$. The Poisson's ratio for both the materials is taken as 0.3.A square FGM plate of simply supported at all of its edges (SSSS) is considered here. The thickness of the plate (h) is taken $0.02 \mathrm{~m}$ and the aspect ratio $(\mathrm{a} / \mathrm{b})$ is taken unity. The value of the udl $\left(\mathrm{p}_{\mathrm{o}}\right)$ chosen was equal to $1 \mathrm{X} 10^{6} \mathrm{~N} / \mathrm{m}^{2}$.

The mechanical analysis is performed by applying uniformly distributed load (udl) and point load for various boundary conditions SSSS, CCCC, SCSC, CFCF, CCFF, CCSS, SSFF, SSSC, SSSF and SSCF. The abbreviation S, C and F stand for simply supported, clamped and free edges respectively. The boundary conditions imposed at a simply supported (S), a clamped (C) and a free (F) edge are:

Simply supported (S) $\sigma_{\mathrm{xx}}=0 ; \mathrm{v}=\mathrm{w}=0$; on $\mathrm{x}=0$ and $\mathrm{a}$; and $\sigma_{\mathrm{yy}}=0 ; \mathrm{u}=\mathrm{w}=0$; on $\mathrm{y}=0$ and $\mathrm{b}$;

Clamped (C) : $\mathrm{u}=\mathrm{v}=\mathrm{w}=0$; on $\mathrm{x}=0$, a and $\mathrm{y}=0, \mathrm{~b}$;

Free $(\mathrm{F}): \sigma_{\mathrm{xx}}=\sigma_{\mathrm{yx}}=\sigma_{\mathrm{zx}}=0$; on $\mathrm{x}=0$ and $\mathrm{a}$; and $\sigma_{\mathrm{yy}}=\sigma_{\mathrm{xy}}=\sigma_{\mathrm{zy}}=0$; on $\mathrm{y}=0, \mathrm{~b}$

The analysis is performed for E-FGM and for various values of the volume fraction exponent (n) in P-FGM and S-FGM. The results are presented in terms of non-dimensional parameters i.e. non-dimensional deflection $(\overline{u z})$, nondimensional tensile stress $(\overline{\sigma x})$ and shear strain $\left(\mathrm{e}_{\mathrm{xy}}\right)$.

The various non-dimensional parameters used are:

Non-dimensional deflection $\overline{u z}=\left(100 \mathrm{E}_{\mathrm{m}} \mathrm{h}^{3} \mathrm{u}_{\mathrm{z}}\right) /\left(1-v^{2}\right) \mathrm{a}^{4} \mathrm{p}_{\mathrm{o}}$

And non-dimensional stress $\overline{\sigma x}=\sigma \mathrm{h}^{2} / \mathrm{p}_{\mathrm{o}} \mathrm{a}^{2}$

where ' $u_{\mathrm{z}}$ ' is deflection, ' $\sigma$ ' is stress, ' $v$ ' Poisson's ratio $(0.3)$.

\subsection{Non-dimensional deflection $(\overline{u z})$}

Figure 6, Figure7and Figure 8shows the comparative bar charts of non-dimensional deflection $\mathrm{u}_{\mathrm{z}}$ for various boundary conditions of a square plate under uniformly distributed load for P-FGM, S-FGM and E-FGM 
respectively. In case of P-FGM and S-FGM the comparison of various values of volume fraction exponent (n) have been presented. In case of E-FGM a single graph is obtained.

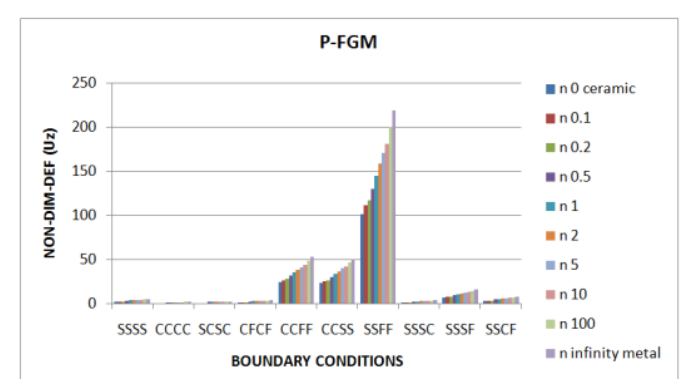

Figure6: Non-dimensional deflection $\mathrm{u}_{\mathrm{z}}$ for various boundary conditions (P-FGM)

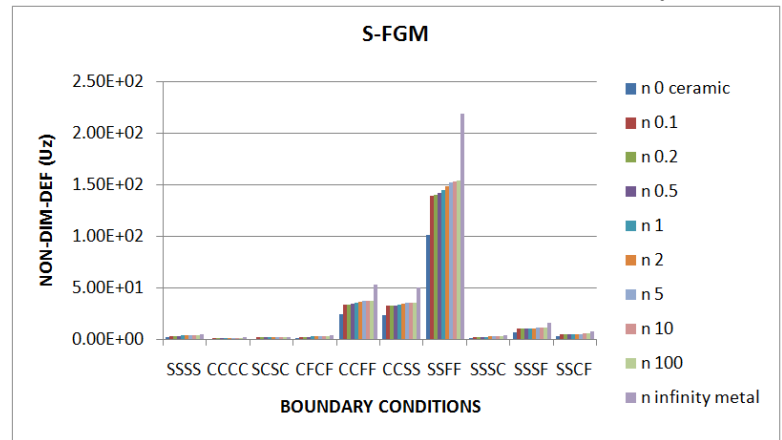

Figure 7: Non-dimensional deflection $\mathrm{u}_{\mathrm{z}}$ for various boundary conditions (S-FGM)

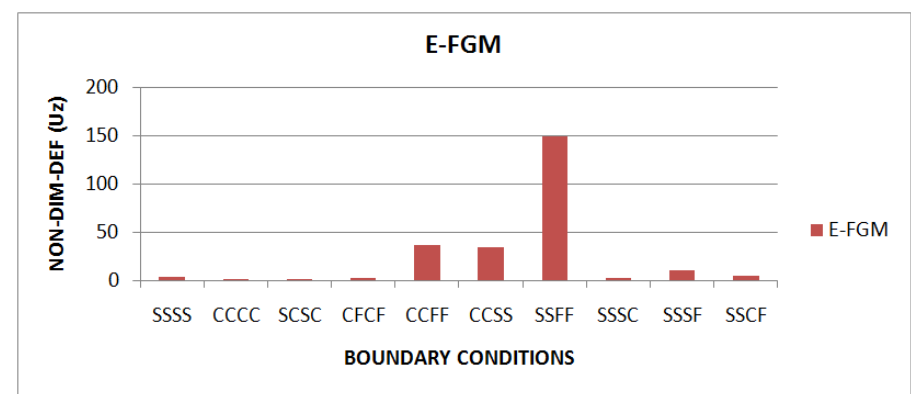

Figure8: Non-dimensional deflection $\mathrm{u}_{\mathrm{z}}$ for various boundary conditions (E-FGM)

It can be observed that the isotropic ceramic plate has the lowest deflection for all the boundary conditions considered here, and the isotropic metallic has the largest deflection. The deflections become higher with increasing $n$. This is due to the fact that the bending stiffness is the maximum for ceramic plate, while minimum for metallic plate, and degrades continuously as $n$ increases. It is also found that the maximum deflection occurs for simply supported - free (SSFF) boundary conditions and minimum for clamped (CCCC) boundary condition for all the cases considered here. The non-dimensional deflection for S-FGM remains closer for various values of ' $n$ ' as compared to that of the P-FGM.

\subsection{Non-dimensional tensile stress $(\overline{\sigma x})$}

Figure 9, Figure 10 and Figure 11 shows the variation of non-dimensional tensile stress $\left(\sigma_{\mathrm{x}}\right)$ for various boundary conditions of a square plate under uniformly distributed load for P-FGM, S-FGM and E-FGM respectively. In case of P-FGM and S-FGM the comparison of various values of volume fraction exponent (n) have been presented. In case of E-FGM a single graph is obtained. 


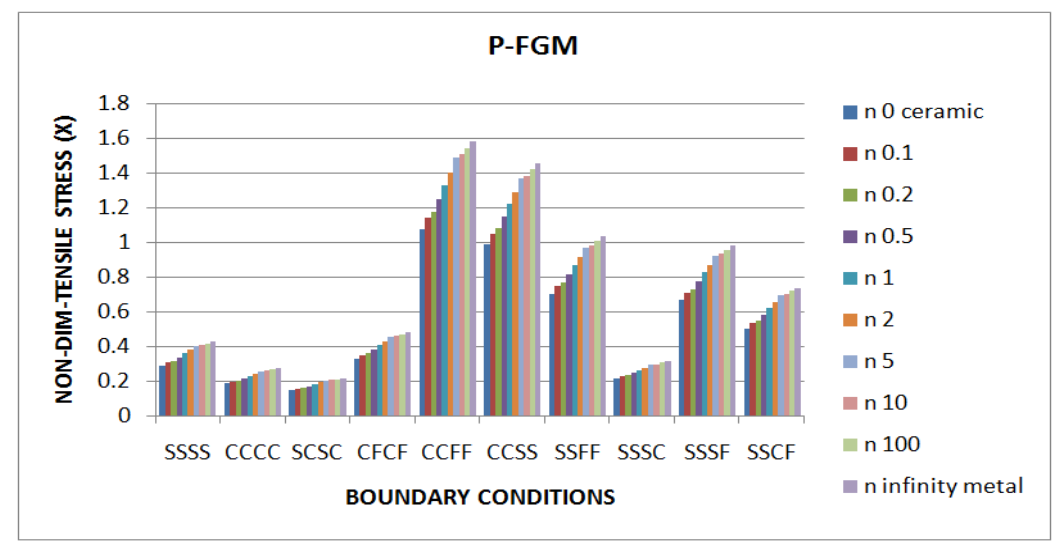

Figure9: Non-dimensional tensile stress $\left(\sigma_{\mathrm{x}}\right)$ for various boundary conditions (P-FGM)

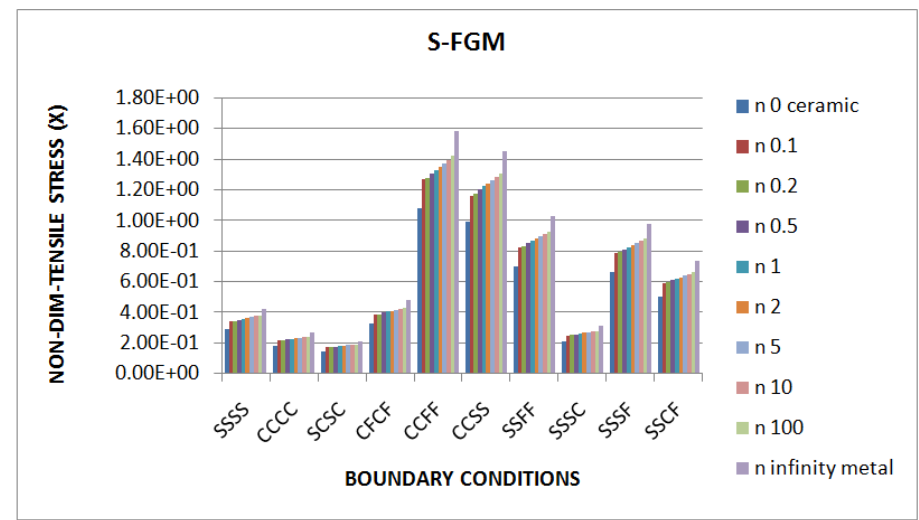

Figure 10: Non-dimensional tensile stress $\left(\sigma_{x}\right)$ for various boundary conditions (S-FGM)

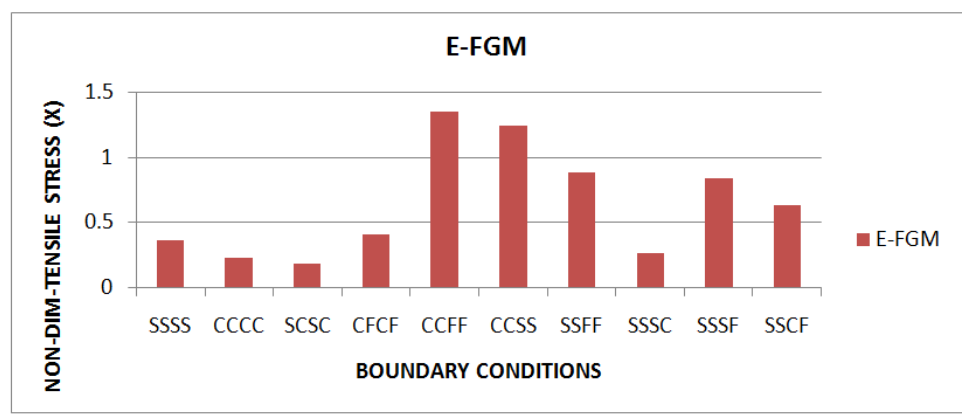

Figure 11: Non-dimensional tensile stress $\left(\sigma_{\mathrm{x}}\right)$ for various boundary conditions (E-FGM)

It can be observed that the isotropic ceramic plate has the lowest tensile stress for all the boundary conditions considered here, and the isotropic metallic has the largest tensile stress. The tensile stress becomes higher with increasing $n$. This is due to the fact that the bending stiffness is the maximum for ceramic plate, while minimum for metallic plate, and degrades continuously as $n$ increases. It is also found that the maximum tensile stress occurs for clamped - free (CCFF) boundary conditions and minimum for simply supported clamped (SCSC) boundary condition for all the cases considered here. The non-dimensional tensile stress for SFGM remains closer for various values of ' $n$ ' as compared to that of the P-FGM.

\subsection{Shear strain $\left(\mathrm{e}_{\mathrm{xy}}\right)$}

Figure 12, Figure 13 and Figure 14 shows the variation of Strain $\left(\mathrm{e}_{\mathrm{xy}}\right)$ for various boundary conditions of a square plate under uniformly distributed load for P-FGM, S-FGM and E-FGM respectively. In case of PFGM and S-FGM the comparison of various values of volume fraction exponent (n) have been presented. In case of E-FGM a single graph is obtained. 


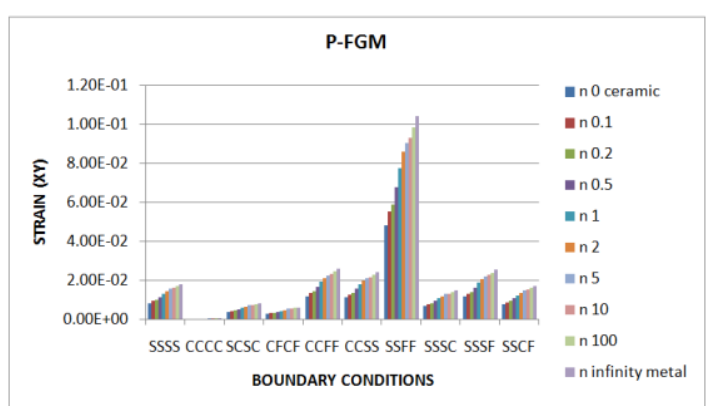

Figure 12: Shear Strain $\left(\mathbf{e}_{\mathbf{x y}}\right)$ for various boundary conditions of a square plate (P-FGM)

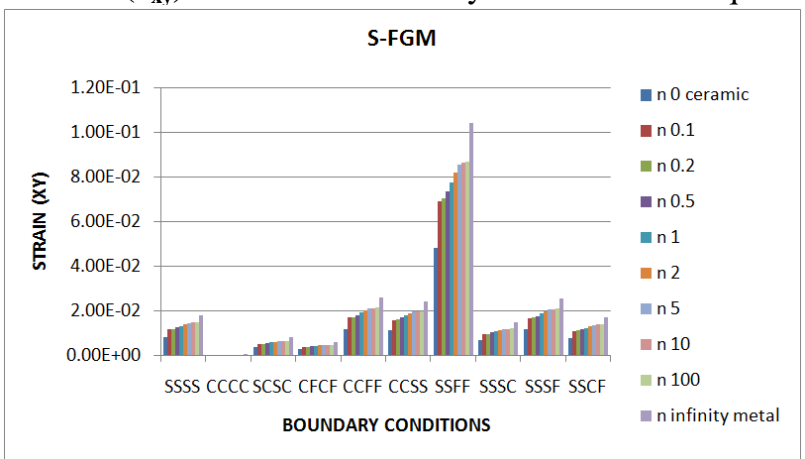

Figure 13: Shear Strain $\left(\mathbf{e}_{\mathbf{x y}}\right)$ for various boundary conditions of a square plate (S-FGM)

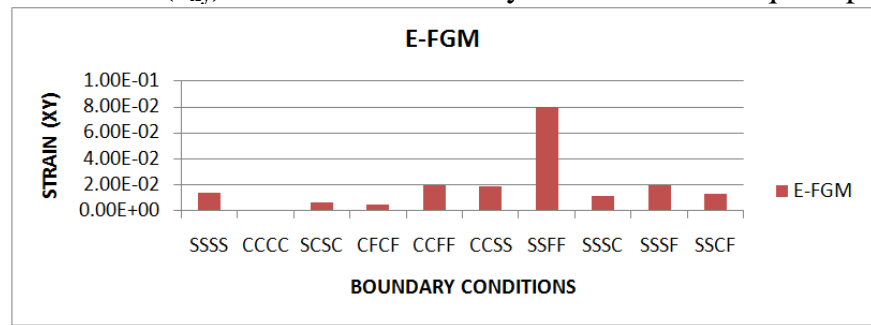

Figure 14: Shear Strain $\left(\mathbf{e}_{\mathbf{x y}}\right)$ for various boundary conditions of a square plate (E-FGM)

It can be observed that the isotropic ceramic plate has the lowest Strain $\left(\mathbf{e}_{\mathbf{x y}}\right)$ for all the boundary conditions considered here, and the isotropic metallic has the largest Strain $\left(\mathbf{e}_{\mathrm{xy}}\right)$. The Strain $\left(\mathbf{e}_{\mathrm{xy}}\right)$ becomes higher with increasing $n$. This is due to the fact that the bending stiffness is the maximum for ceramic plate, while minimum for metallic plate, and degrades continuously as $n$ increases. It is also found that the maximum Strain $\left(\mathbf{e}_{\mathrm{xy}}\right)$ occurs for simply supported - free (SSFF) boundary conditions and minimum for clamped (CCCC) boundary condition for all the cases considered here. The shear strain $\left(\mathrm{e}_{\mathrm{xy}}\right)$ for S-FGM remains closer for various values of ' $n$ ' as compared to that of the P-FGM

\section{Conclusions and future scope}

Mechanical deformation of functionally graded ceramic-metal plates under various boundary conditions is analyzed. Convergence and validation studies have been carried out to inculcate the accuracy of the present formulation. The results show a good agreement with those available in the literature. It is observed that

(a) The bending response of the functionally graded plate is intermediate to those of the metal and the ceramic plate. This behavior is found to be true irrespective of boundary conditions.

(b) The bending response for S-FGM remains closer for various values of ' $n$ ' as compared to that of the PFGM.

(c) The bending response of E-FGM is nearer to the behavior of P-FGM. The work can be extended for variation in load, loading pattern and other ceramic metal combinations. Also thermal environment may be imposed in addition to the mechanical loading.

\section{References:}

[1] G. N. Praveen and J. N. Reddy, "Nonlinear transient thermoelastic analysis of functionally graded ceramic-metal plates", Int. J. Solids Structure, 35, 4457- 4476, 1997.

[2] J. N. Reddy, "Thermomechanical behavior of functionally graded materials", Final Report for AFOSR Grant F49620-95-1-0342, CML Report 98-01, August 1998.

[3] Z.Q. Cheng and R.C.Batra, "Three-dimensional thermoelastic deformations of a functionally graded elliptic plate", Composites Part B, 31(1), 97-106, 2000. 


\section{Analysis of Functionally graded material plate under transverse load for various boundary}

[4] J. N. Reddy, “Analysis of functionally graded plates”, Int. J. for numerical methods in engg., Int. J. Numer. Meth. Engg., 47, 663$684,2000$.

[5] Bhavani V. Sankar and Jerome T. Tzeng, "Thermal stresses in functionally graded beams", AIAA journal, 40, 1228-1232, 2002.

[6] L.FQian, R. C. Batra, and L. M. Chen "Static and dynamic deformations of thick functionally graded elastic plates by using higher order shear and normal deformable plate theory and meshless local Petrov-Galerkin method" , Composite Part B, 35, 685-697, 2004.

[7] A. J. M. Ferreira, R.C. Batra, C.M.C. Roque, L.F. Qian, and P.A.L.S. Martins, "Static analysis of functionally graded plates using third order shear deformation theory and a meshless method", Compo. Struct., 69, 449-457, 2005.

[8] M. Tahani1, M. A. Torabizadeh and A. Fereidoon, "Non-Linear Response of Functionally graded beams under transverse loads" $14^{\text {th }}$ Annual (International) Techanical Engineering Conference ,Isfahan University of Technology, Isfahan, Iran, May 2006.

[9] Shyang-Ho Chi and Yen-Ling Chung, "Mechanical behavior of functionally graded material plates under transverse load-Part I: Analysis", Int. J. of Solids and Structures, 43, 3657-3674, 2006

[10] Shyang-Ho Chi and Yen-Ling Chung, "Mechanical behavior of functionally graded material plates under transverse load-Part II: Numerical results", Int. J. of Solids and Structures, 43, 3675-3691, 2006.

[11] Hui Wang and Qing-Hua Qin, "Meshless approach for thermo-mechanical analysis of functionally graded materials, Engineering Analysis with Boundary Elements", 32, 704-712, 2008.

[12] Yasser M. Shabana andNaotake Noda, "Numerical evaluation of the thermomechanical effective properties of a functionally graded material using the homogenization method", Int. J. of Solids and Structures, 45, 3494-3506,2008

[13] M. Mahdavian, "Buckling Analysis of Simply-supported Functionally Graded Rectangular Plates under Non-uniform In-plane Compressive Loading", J. of Solid Mechanics, 1, 3, 213-225, 2009,

[14] Ashraf M. Zenkour and Daoud S. Mashat, "Thermal buckling analysis of ceramic-metal functionally graded plates", Natural Science, 2, No.9, 968-978, 2010

[15] S.S. Alieldin, A.E. Alshorbagy and M. Shaat, "A first-order shear deformation finite element model for elastostatic analysis of laminated composite plates and the equivalent functionally graded plates", Ain Shams Engg. J., 2, 53-62, 2011

[16] Kyung-Su Na, and Ji-Hwan Kim, "Comprehensive Studies on Mechanical StressAnalysis of Functionally Graded Plates", World Academy of Science, Engg. and Tech., 60, 768-773, 2011

[17] Vanam B. C. L., Rajyalakshmi M. and Inala R., "Static analysis of an isotropic rectangular plate using finite element analysis (FEA)", J. of Mech.Engg. Research, 4(4), 148-162, 2012.

[18] Mostapha Raki, Reza Alipour and Amirabbas Kamanbedast, “Thermal Buckling of Thin Rectangular FGM Plate”, World Applied Sciences J., 16 (1): 52-62, 2012.

[19] Mohammad Talha and B N Singh, "Thermo-mechanical deformation behavior of functionally graded rectangular plates subjected to various boundary conditions and loadings,'Int. J. of Aerospace and Mech. Engg., 6:1, 14-25, 2012.

[20] Srinivas.G and Shiva Prasad.U, "Simulation of Traditional Composites Under Mechanical Loads", International Journal of Systems", Algorithms \& Applications, 2, 10-14,2012

[21] Srinivas.G and Shiva Prasad .U, "Simulation of Traditional Composites Under Thermal Loads", Research J. of Recent Sciences, 2, 273-278, 2013 